\title{
Categorizing and Ranking Graphs in the American Economic Review Over the Last Century
}

\author{
Jonathan Schwabish \\ Urban Institute and PolicyViz \\ August 2018
}

\begin{abstract}
The American Economic Review (AER) is one of the most prestigious journals in the field of economics. First published in 1911, the journal has published articles covering every aspect and topic in the field. AER articles are not just in-depth prose; they might also include tables, diagrams, and graphs. In this paper I ask two primary questions: First, do most graphs in the AER use data or are they somc kind of diagram or illustration of a theory or concept? Second, what kinds of graphs-lines, bars, pies, etc.-do economists use to help visualize their arguments in the AER? And third, are those graphs of generally high quality? To help shed some light on those questions, I collect, catalog, and-using Amazon's Mechanical Turk platform-rate every graph in the first volume of the AER from 1911 to 2017. I find that the share of graphs that use data fell over the first half of the century and then increased from about the early 1980s to today. I also find that economists use a lot of line charts-of the more than 2,600 graphs in total, more than $80 \%$ are line charts. Finally, I find a $U$-shaped curve in perceived graph quality, falling to a low in the early-1960s and rising over the past several decades, on average reaching a level only slightly higher than in the first issues. This research is the first step in understanding how economists use data visualization to communicate their work and can help provide a basis for effective strategies that will enable better communication of that work.
\end{abstract}

\footnotetext{
* I'd like to thank Steve Haroz, Lane Harrison, and Donald Marron for helpful suggestions and comments. This is a draft paper and should not be cited without permission of the author. Comments can be sent directly to sschwabish@gmail.com.
} 


\section{Introduction}

First published in 1911, The American Economic Review stands as one of the most prestigious journals in the field of economics. Thousands of articles published over the last 117 years raises a question of design: How have economists used graphs to help visualize their arguments? What kinds of graphs do they use and are those graphs of high quality? Here, I collect, catalog, and rate every graph-more than 2,600 in total-in the first volume of the AER from 1911 to 2017.

Data visualization - the act of effectively visualizing data to help communicate data, analysis, or an argument-has always been part of the economists' toolbox. Whether as part of the data exploration phase to better understand the underlying data or the structural model, the graph or chart inserted in the working paper or journal article, or as part of a conference presentation, graphs provide evidence or reinforce a point or argument. In his book Brain Rules, developmental molecular biologist John Medina writes that "The more visual an input becomes, the more likely it is to be recognized and recalled." In other words, visuals help make a hypothesis, argument, or result stick in the reader's, user's, or audience member's mind.

\section{Short History of Data Visualization in the AER}

The first graph published in the March volume of the AER was "Chart 1" from E.W. Kemmerer's article, "Seasonal Variations in the New York Money Market 1890-1908." A simple line chart shows changes in interest rates, bank reserves, and bank clearings during that period, to which Kemmerer remarks, "The best criterion of deposit currency is found in bank clearings, and the seasonal variations in New York clearings for the period 1890-1908 are given in the table (opposite p. 40) and shown in Chart 1 (curve D). A glance at these figures and at the corresponding curve shows that the season swings of bank clearings in New York city confirm fairly closely to the five seasonal swings which we have found for the New York money market." Well before the invention of Microsoft Excel, Stata, or even computers, Kemmerer was plotting multiple data series and writing the labels, legends, and titles by hand.
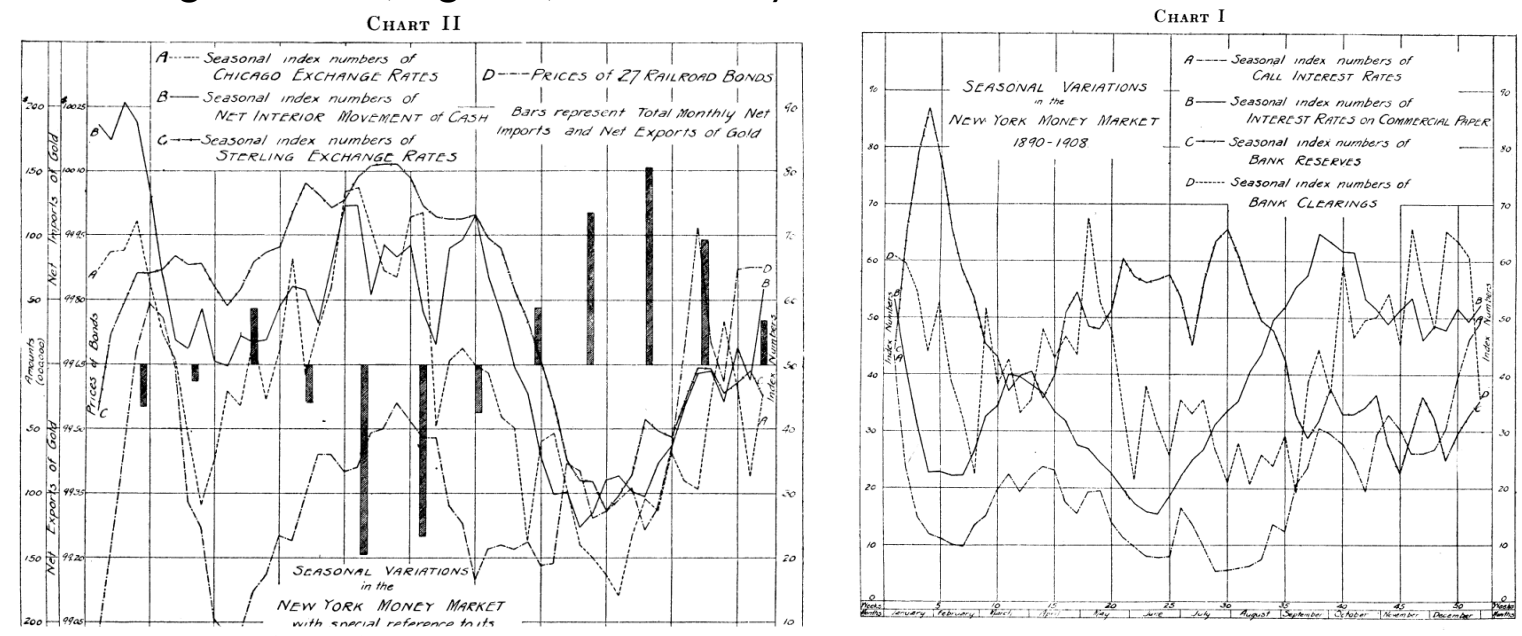

Source: Kemmerer (1911). 
Margo (2011) describes the history of the AER, so I leave the details to the interested reader, but three items in that account are perhaps of particular interest to this paper. First, 1968 was the last year in which the AER published book reviews-the last volume in 1968 was 1,523 pages, nearly 500 pages more than the first volume in 1969 without book reviews. On the whole, book reviews tend to not include graphs or figures, which will certainly affect the graph and table counts presented below. Second, the parent organization of the AER, the American Economic Association (AEA), developed new journals over the past hundred years, that served to change the types of papers submitted (and ultimately published) to the journal. This might also impact the types and quality of graphs published in the AER over time.

Finally, the number of submitted papers to the AER grew swiftly in the 1950s and 1960s. There were about 200 papers submitted to the AER in 1950, which rose to 637 in 1968. During the early 1970 s, the number of submitted papers declined slightly, likely because of the introduction of new journals. Submissions then climbed in the early 1980 s before leveling off until about 2000 when they again increased sharply. The average number of papers published remained roughly constant (around 50) throughout the entire period.

The average page length of articles also increased over this latter period, rising from 12.6 pages in 1970 to 16.6 in 1990 to 22.0 in 2005. These trends are all consistent with the larger field of economics publishing, as documented by Card and DellaVigna (2013), who, incidentally, also find that the share of top-5 publications appearing in the AER rose from $25 \%$ in the 1970 s to $40 \%$ in the early-2010s. None of the patterns in the AER would lead to any specific conclusion regarding the number, type, or quality of data visualizations published in the AER, but these time trends could affect any of these patterns.

\section{Methodology}

The task of collecting, categorizing, and rating AER visualizations requires creating a database of all graphs and tables in the AER and then using workers in Amazon's Mechanical Turk (MTurk) to categorize and rate the graphs.

\section{Step 1: Collect AER Graphs and Tables}

In the first step, I collected screenshots of every graph and table in the AER in the first AER volume from 1911 through 2017 (the first volume was issued in March until 2011 when it changed to February). I found a freelancer using the Upwork platform (www.upwork.com) to collect screenshots of each image and catalog the citation data (financial support was provided by my independent consulting firm, PolicyViz). Every journal article-whether it had a graph/table or not-was entered into a database with the author(s) name(s), title, issue number, volume number, JSTOR URL, year, page numbers, article number (article number being a number we assigned as the article's position in the volume), and the total number of graphs and tables. Screenshots of each exhibit were taken and saved. 
The question of what to do with separate charts that are paired together was something I tried to handle consistently. Graphs that appeared on the same page and that were named with a single title I considered a single visualization. As you can see below, Charts 1, 2, and 3 in Abbot Usher's 1916 paper all appear on the same page, but have the same title, so they are treated as one image. Graphs that appeared on the same page but were named separately were considered separate visualizations. Kemmerer's charts above appeared on the same page in his 1911 article, but they are named separately; for purposes of this study, these are considered separate charts.
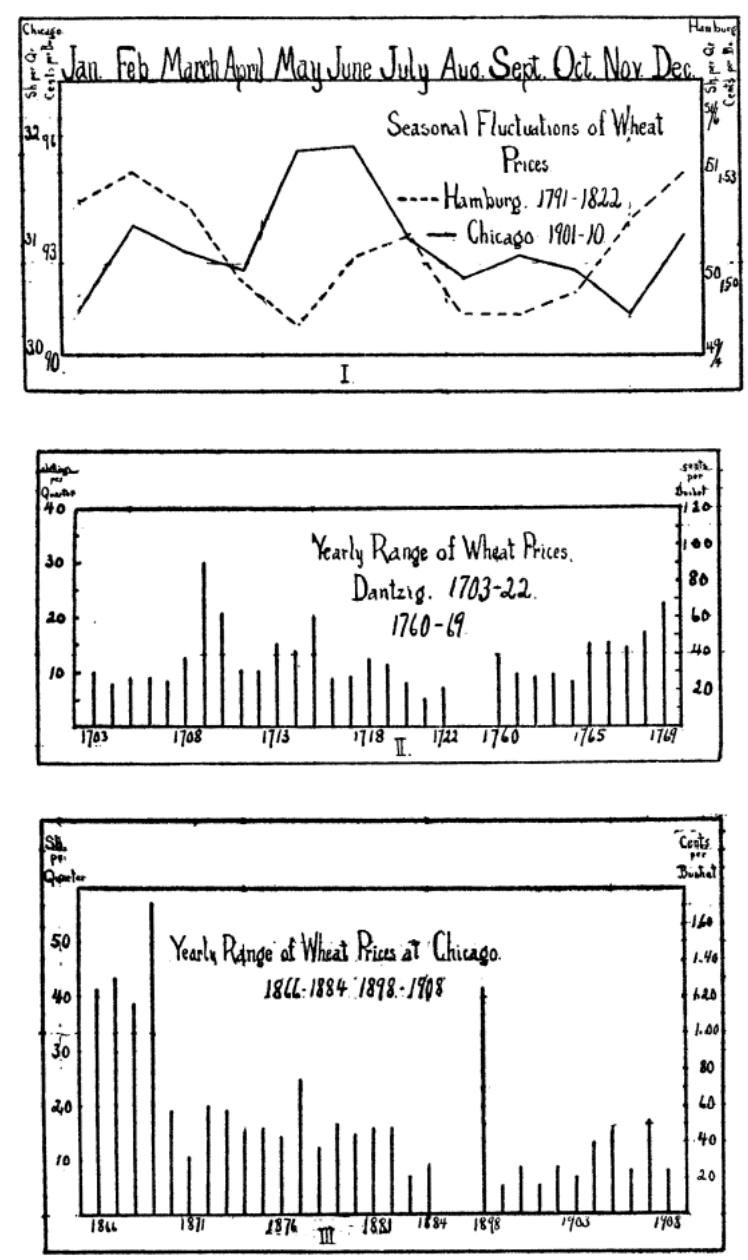

- Charts, I, II, and III.

Source: Usher (1916).

I also chose figures based on their name-"Charts" and "Figures" were collected in this data set, even if an exhibit might arguably be considered a table. For example, this image from Aumann and Dreze's 2008 paper is labeled "Figure 5" but is arguably a table. These exhibits are included in the database and are categorized as tables. 


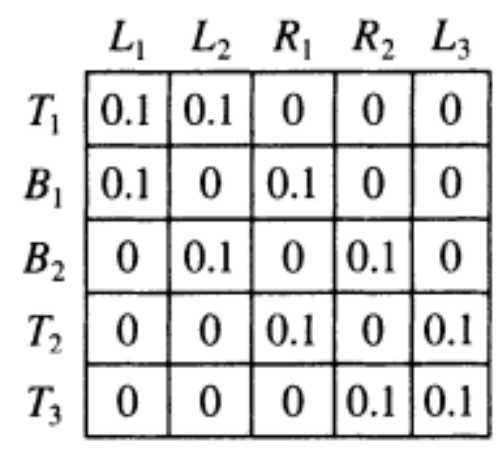

FIGURE 5

The common prior

Source: Aumann and Dreze (2008).

Step 2: Categorize the Graphs using Amazon's Mechanical Turk In the second step, I used the Amazon Mechanical Turk (MTurk) to categorize and rate each graph. The MTurk is a holding of Amazon Web Services and owned by Amazon. It is a crowdsourcing marketplace for "for work that requires human intelligence." In MTurk, individuals and businesses-known as Requesters-can request small tasks from workers, who are known as Turkers. Such tasks might include categorization, data verification, photo moderation, tagging, transcription, or translation. Requesters submit their jobs with a price per unit (whatever unit they choose), which Turkers may or may not accept. A job on MTurk is known as a Human Intelligence Task, or HIT, and by definition is a "single, self-contained task that a Worker can work on, submit an answer, and collect a reward for completing" (Amazon, 2018).

There is an existing literature about the accuracy of MTurk and the characteristics of Turkers. Mason and Suri (2011) collected demographic information for nearly 3,000 different Turkers and found that of those who chose to report their gender, about 55\% were women. The median reported age in their sample was 30 years old and the average 32 years old. The majority of Turkers in the study reported earning roughly $\$ 30,000$ per year. Ipeirotis (2010) found that about $12 \%$ of US Turkers and $27 \%$ of Indian Turkers reported that the earnings from the Turk was their primary source of income, and roughly $30 \%$ of each group was unemployed or working part-time.

Many other researchers have used MTurk to rate or review data visualizations. Heer and Bostock (2010), for example, used it to replicate previous laboratory studies on the accuracy of different data encodings such as length (e.g., bar charts), angle (e.g., pie charts), and area (e.g. bubble chart). Harrison et al (2014) tested perceptions of correlation by asking Turkers to identify graphs that plot higher levels of correlation (across nine different chart types). Other researchers have tested perceptions of pie charts (Skau and Kosara 2016), memorability (Borkin et al 2013), and the impact of chart embellishment on understanding (Skau et al 2015). 
Obviously, the MTurk is not without flaws. It's hard to know whether the Turker is actually answering the questions or simply checking a box quickly. Turkers are not in a controlled environment, as they might be in a laboratory. In some cases, votes can be "flooded" to skew the results in particular ways. And because I don't have any identifying information about the Turkers, I can't be sure I have a representative sample to accomplish the tasks (see also Kosara and Ziemkiewicz, 2010). The results might differ if, say, $\mathrm{PhD}$ economists or data visualization specialists rated each graph (see the Additional Caveats section below).

The project was defined to have five different people rate each graph, but any single Turker could rate as many graphs as they like. Turkers were paid $\$ 0.03$ per graph and the median amount of time to complete a HIT was about 17 seconds. Overall, 70 Turkers rated graphs with five Turkers rating 1,400 or more graphs and 10 Turkers rating only one graph. Seven Turkers rated between 100 and 1,000 graphs with the remainder (39 Turkers), rating between two and 100 graphs. The graphs are randomized so that Turkers see graphs in a random order.

The project description shown to Turkers as as follows: "Categorize a graph (e.g., line, bar, column) and rate the quality of one graph. There are more than 2,600 graphs available to rate." Upon accepting the assignment, Turkers were presented with a bit of explanatory text (see Figure 1) and a link to a Google Doc (see Appendix A) that contained more details and examples.

\section{Figure 1. Turker Instructions}

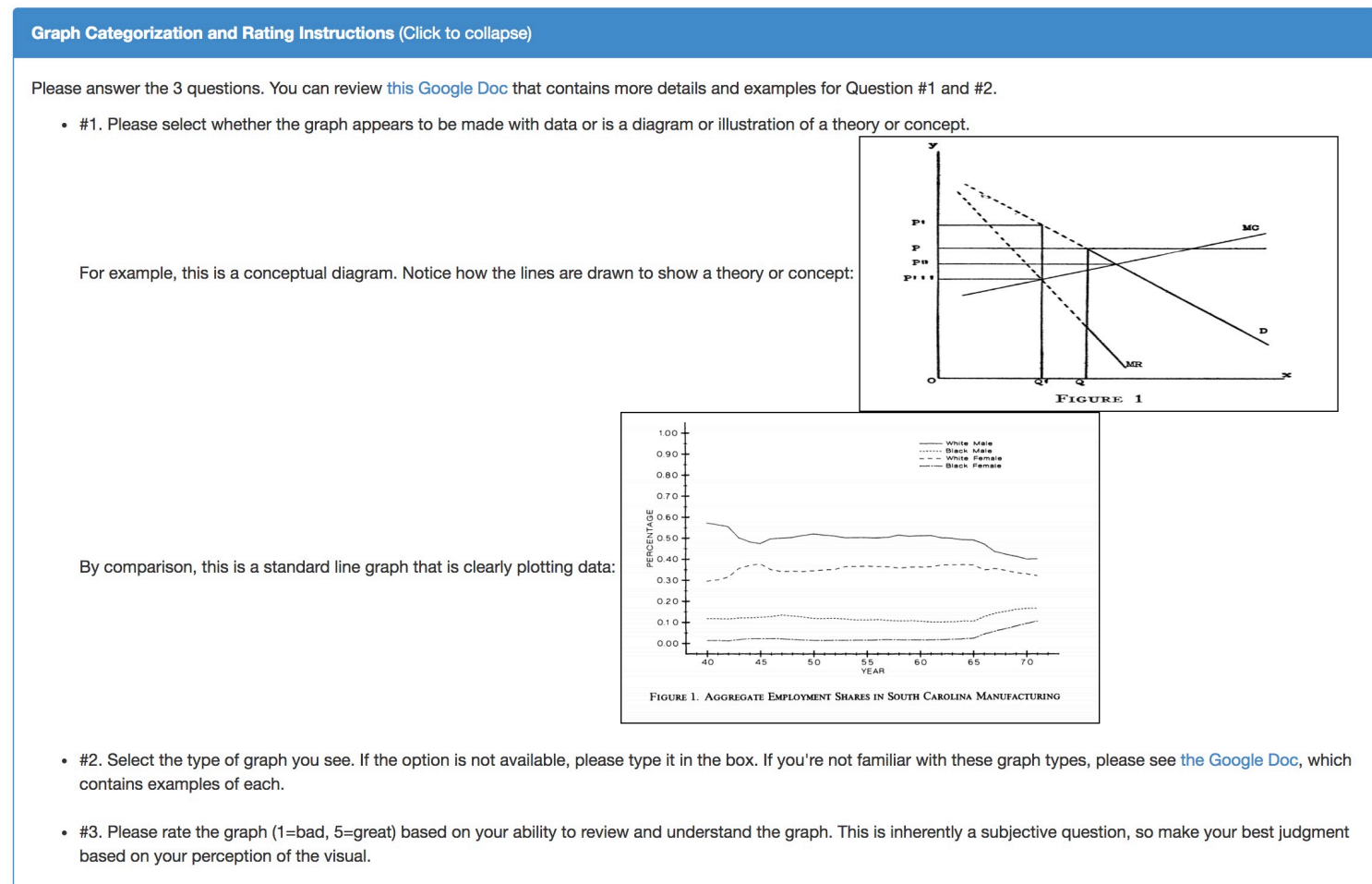

Note: First Graph: Bronfenbrenner (1947); Second Graph: Heckman and Payner (1989). 
Turkers were asked to answer the following three questions:

\#1. Is this graph made with data or is it illustrating a concept or theory?

- Data

- Diagram or Illustration

\#2. What type of graph is this?

- Area

- Bar/Column

- Histogram

- Line

- Map

$\circ$ Pie

- Scatterplot

- Table

Other (please type):

\#3. Please rate the quality of this visualization (1=bad, $5=$ great)

$\begin{array}{ll}\circ & 1 \\ \circ & 2 \\ \circ & 3 \\ \circ & 4 \\ \circ & 5\end{array}$

There was only one possible response for question \#1 and \#3. For question \#2, the Turker could enter an additional response in a box provided under the "Other" category. Some responses included in this category included "timeline", "decision tree", "venn diagram", and "countour plot". These answers were corrected for spelling and capitalization in order to quantify the results.

Rating the quality of a visualization is inherently subjective; I gave the Turkers no other information except to note in the Google doc that, "This is inherently a subjective question, so make your best judgment based on your perception of the visual." Rating a graph is likely dependent upon the context of the visuals and whether the reviewer has any background or interest in the topic.

\section{Additional Caveats}

Although rerunning any survey might ultimately generate different findings (e.g., McGovern and Bushery 1999), this might be especially true with the Mechanical Turk. With more or fewer Turkers rating and reviewing each graph, the overall pattern might change. It's also the case that not providing raters with the context behind the graphthat is, the rest of the journal article-will likely affect their perception of the quality of the graphs (obviously, asking raters to read more than 700 articles is not feasible).

It's also the case that the Turkers may not have sufficient experience with graphs in economics or data visualization to accurately reflect their impact, accuracy, or usefulness. Extensions to this paper could include asking a set of economists to rate and review the graphs. Another avenue for study could be to ask data visualization experts to 
rate and review the graphs; in that case, the expertise shifts from the content of the graphs to the quality of the graphs themselves.

\section{Changes in the Number of Graphs and Pages since 1911}

There are more than 2,600 graphs (plus more than 3,500 tables) in the first volume of the AER from 1911 and 2017 (across 740 different articles). AER issues are 303 pages in length, on average, not including pages with roman numerals. As Margo (2011) noted, the length of the AER has grown over time, rather more quickly after about 1963 (see also Card and DellaVigna 2013). The first volume in each year more or less mirrors that trend, though the acceleration really started in the 1980s, but noticeably fell in the last few years (volumes in 1965, 1966, and 1972 combined the first two issues of the year, so although the graphs were collected from the second issue, they were ultimately dropped from the analysis). Figure 2 shows when each of the AER editors managed the journal; the width of the bars shows the average number of pages per year during each editor's tenure.

Figure 2. AER editors and average pages per year

Editor Name, Years Serve Years Served

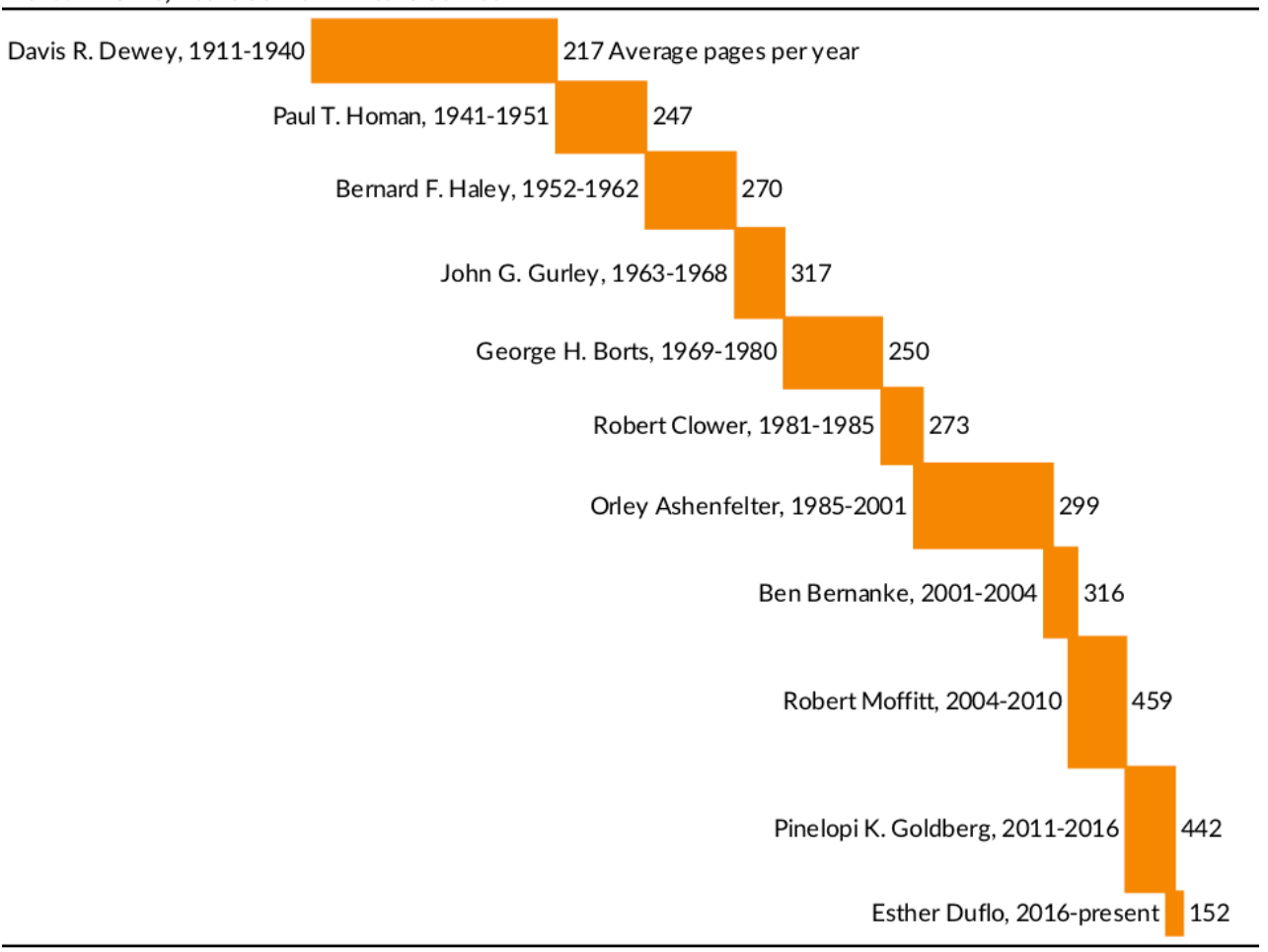

Notes: Height of bars represent average number of pages during each editors tenure; width of bar represents time span of each editor.

Source: Author's calculations; Margo (2011). 
The number of graphs mirrors the number of pages, starting to rise in the late 1930s and reaching a high of 96 graphs in the 2004 and 2009 issues (Figure 3). On a per page basis, there is a similar mostly upward trend; since 2000, there have been about 1-2 graphs for every 10 article pages, or about 3 graphs per article (Figure 4).

Figure 3. The number of graphs and pages in the AER increased starting in the 1980s (Number)

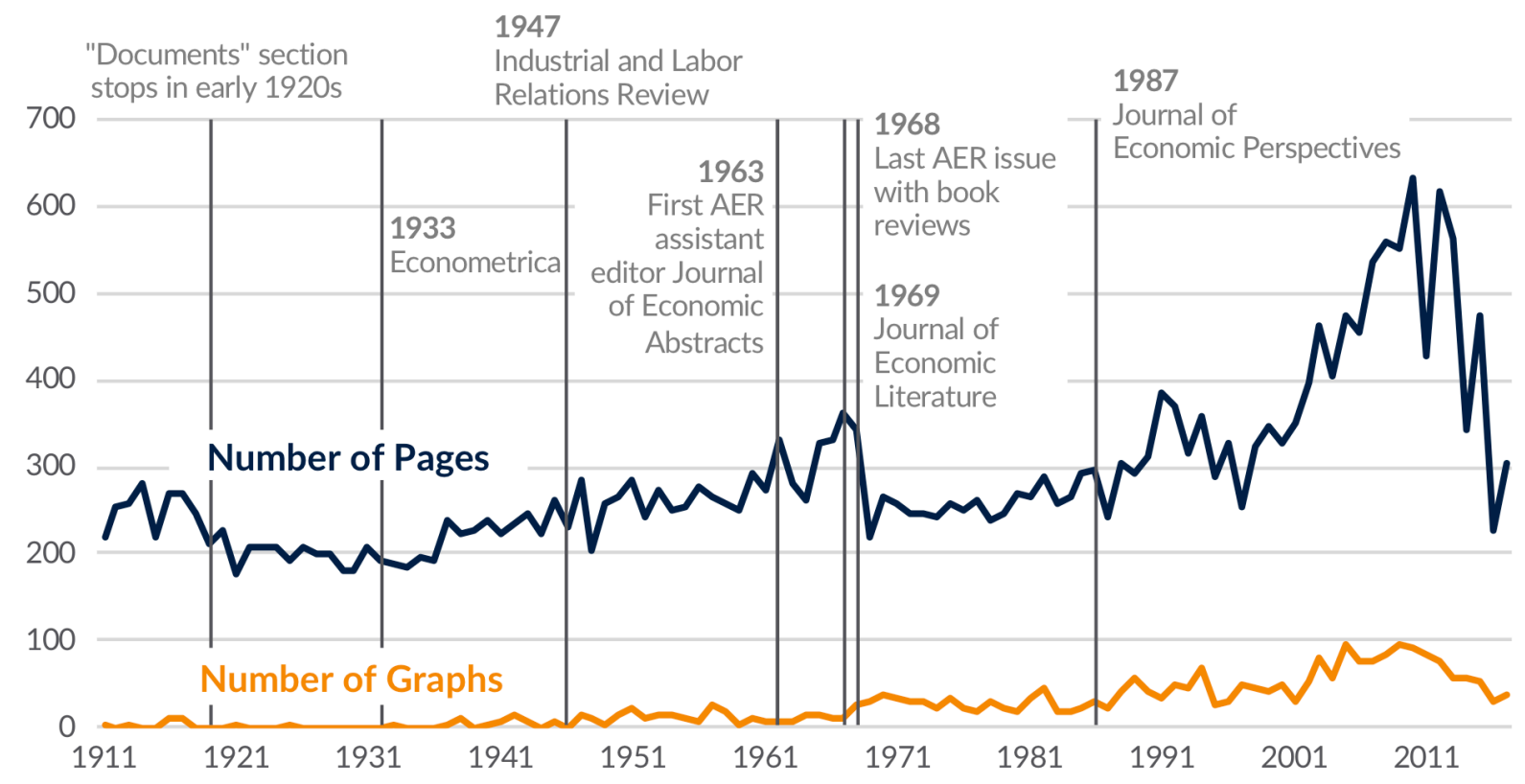

Source: Author's calculations; Margo (2011).

Figure 4 . The number of graphs per page has risen fairly steadily since 1911 (Number of graphs per 10 article pages)

2.5

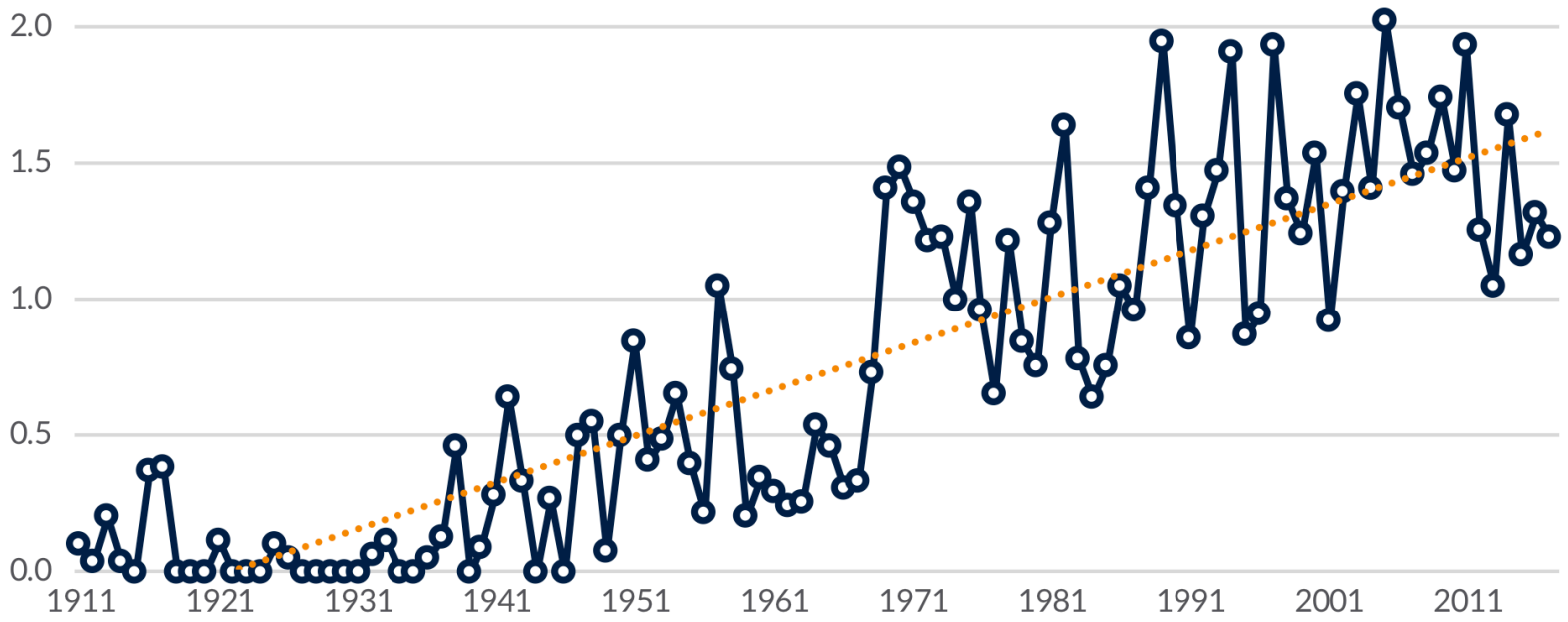

Note: Linear fit in orange.

Source: Author's calculations 


\section{Categorizing Graphs: Diagram/Illustration or Data?}

Graphs do not necessarily need to include data-schematic diagrams, supply-anddemand curves, and utility curves are just some of the visuals economists use to explain economic concepts without explicitly using data. To explore how often economists use these different types of graphs, I asked the Turkers to place graphs into two categories: is the graph made with data or is it a diagram or illustration of a theory or concept?

My initial hypothesis was that, over time, there would be a decline in the share of graphs that are considered a conceptual illustration or diagram and, as computers were invented and grew more powerful and sophisticated, would be replaced with more graphs encoded with data. The results of the MTurk survey yields a slightly more nuanced pattern (see Figure 5). In the early part of the $20^{\text {th }}$ century-up until about 1950 or so-a higher proportion of graphs in the AER were encoded with data (see the Kemmerer graphs above as an example). Then, between roughly the 1960s and early 1990s, a majority of graphs in each year were categorized as diagrams or illustrations. Over the next couple of decades, the share changes again moving towards more graphs encoded with data (except for a dip around 2000); by 2017 , around $70 \%$ of graphs are categorized as graphs with data and the remainder categorized as diagrams or illustrations.

The share of Turkers categorizing graphs as being made with data is calculated as the (unweighted) share of all responses in each year. An alternative approach, in which I first assign classify each graph to be a diagram/illustration or data based on the majority response of the five Turkers, and then calculate the average based on that single aggregate measure yielded similar results (I prepared different calculations in cases where three people categorized the graph as one type). In general, four or five Turkers agreed on about $70 \%$ of the more than 2,600 graphs under review. 
Figure 5. About three-quarters of graphs in recent AERs are encoded with data

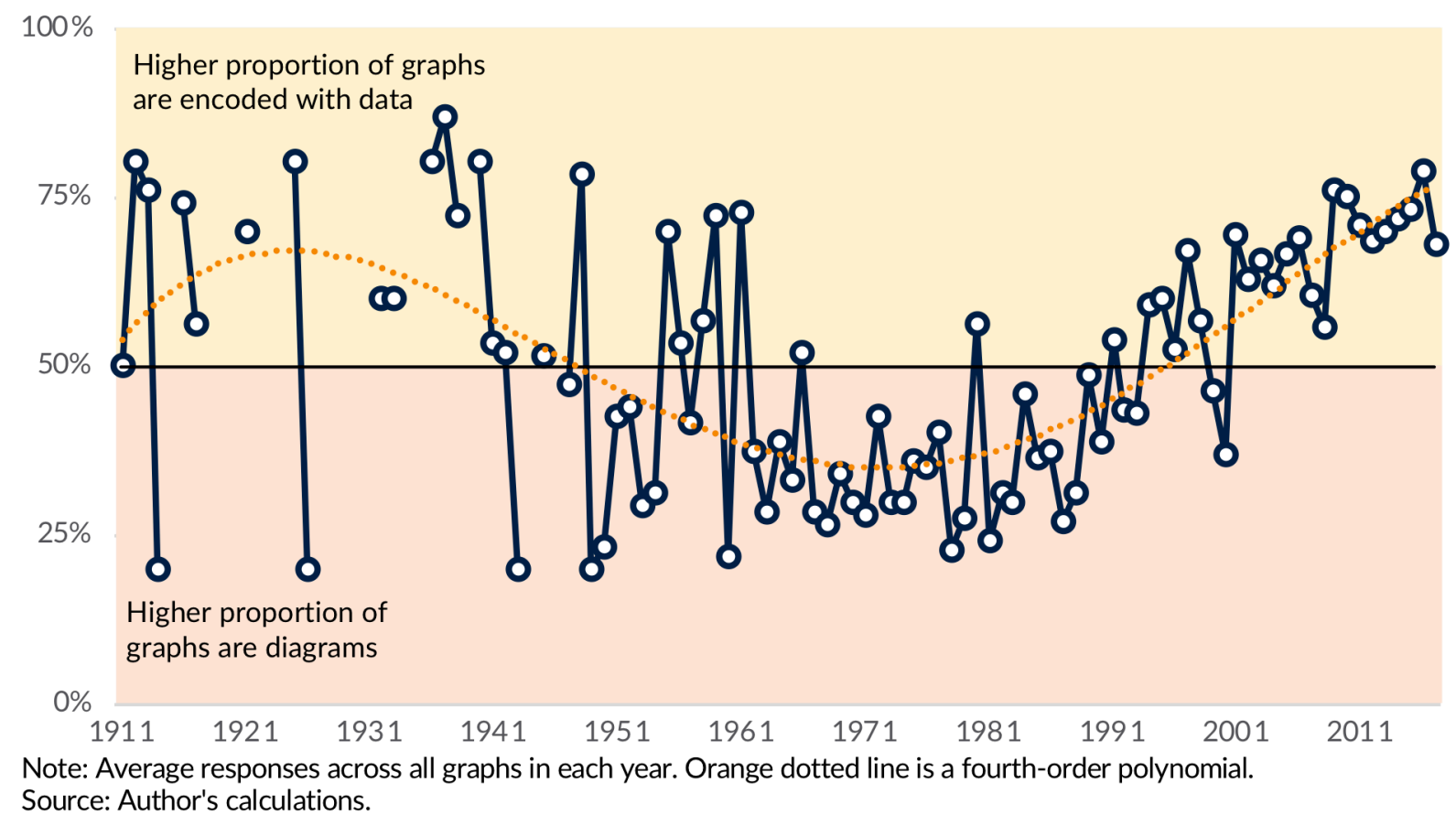

\section{Categorizing the Type of Graphs}

Moving on from whether a graph is a diagram/illustration or encoded with data, the next task is to see what types of graphs economists use. There are virtually unlimited ways to visualize data, ranging from the familiar line, bar, and pie charts to more unfamiliar plot types like network diagrams, slope charts, and dot plots. For purposes of this experiment, I provided the Turkers with a basic library of graphic types from which they could choose (see question \#2 above).

The overwhelmingly most used graph type in the AER is the line chart (Figure 6). Line charts account for more than 80\% of all graphs in the AER over the entire 1911-2017 period. They are used for diagrams, such as supply-and-demand curves, sketched probability distributions, and plotting time series data. The second-most popular graph type over the entire period is the scatterplot, which accounts for $5.7 \%$ of all graphs, followed by the bar chart (3.3\%) and tables (2.1\%).

For these tabulations, I calculate the mode response for each graph type (breaking ties by using the maximum) and then sum the totals in each year. This calculation differs from the previous calculation of diagram-data graph type in that, here, I calculate responses for each graph rather than averaging across all graphs in each year. The reason for using the alternative definition above is that in years with few graphs, the mode response can appear to be $100 \%$ for one graph or another when in truth there is some disagreement between Turkers. 
Figure 6. Economists use line charts

(Number of graphs of each type in each year of the AER)

120

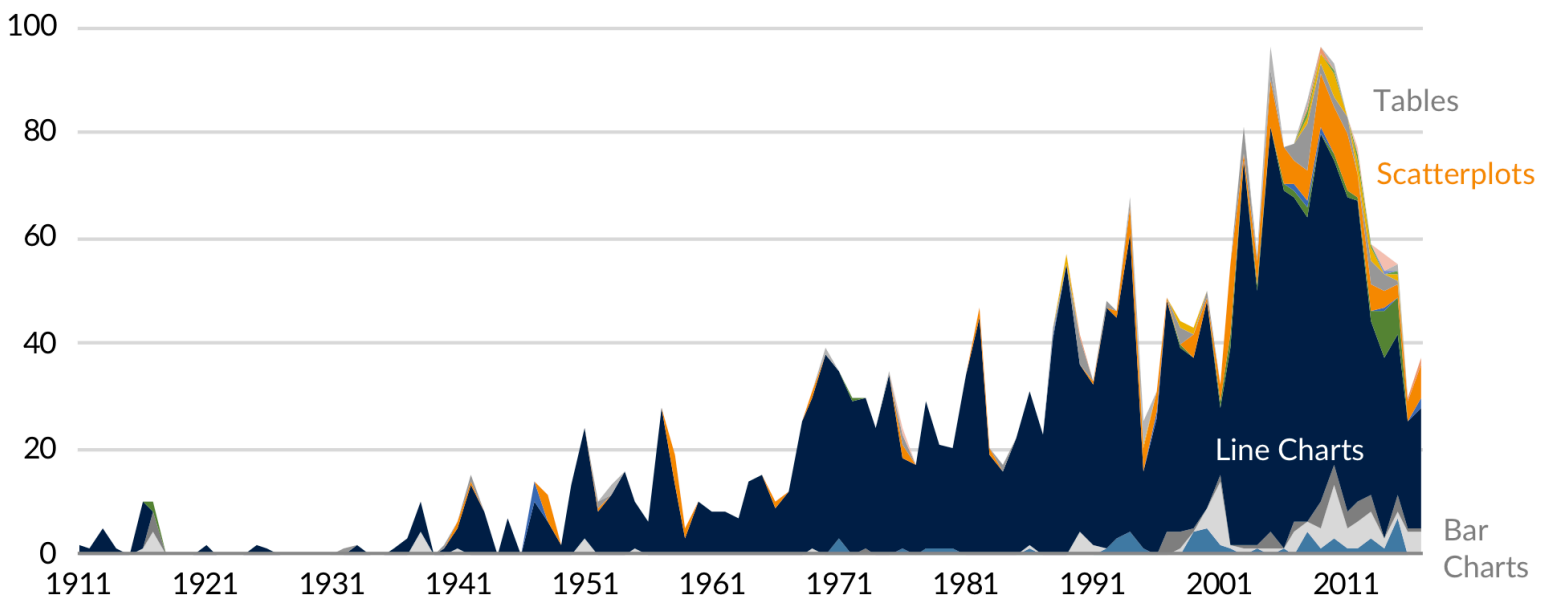

Note: 20 different graphs are plotted, but only the four most common over the entire period are labeled. For other graph types, see text.

Source: Author's calculations.

Perhaps unsurprisingly, the share of graphs that are lines has fallen over time, likely because other graphs have become more popular, more common, and easier to create. Between 1911 and 1990, 92\% of graphs were classified as line charts; over the next 28 years, $75 \%$ of graphs were classified as line charts (see Figure 7).

Figure 7. The share of graphs classified as line graphs has fallen in recent years (Percent of line charts in each year)

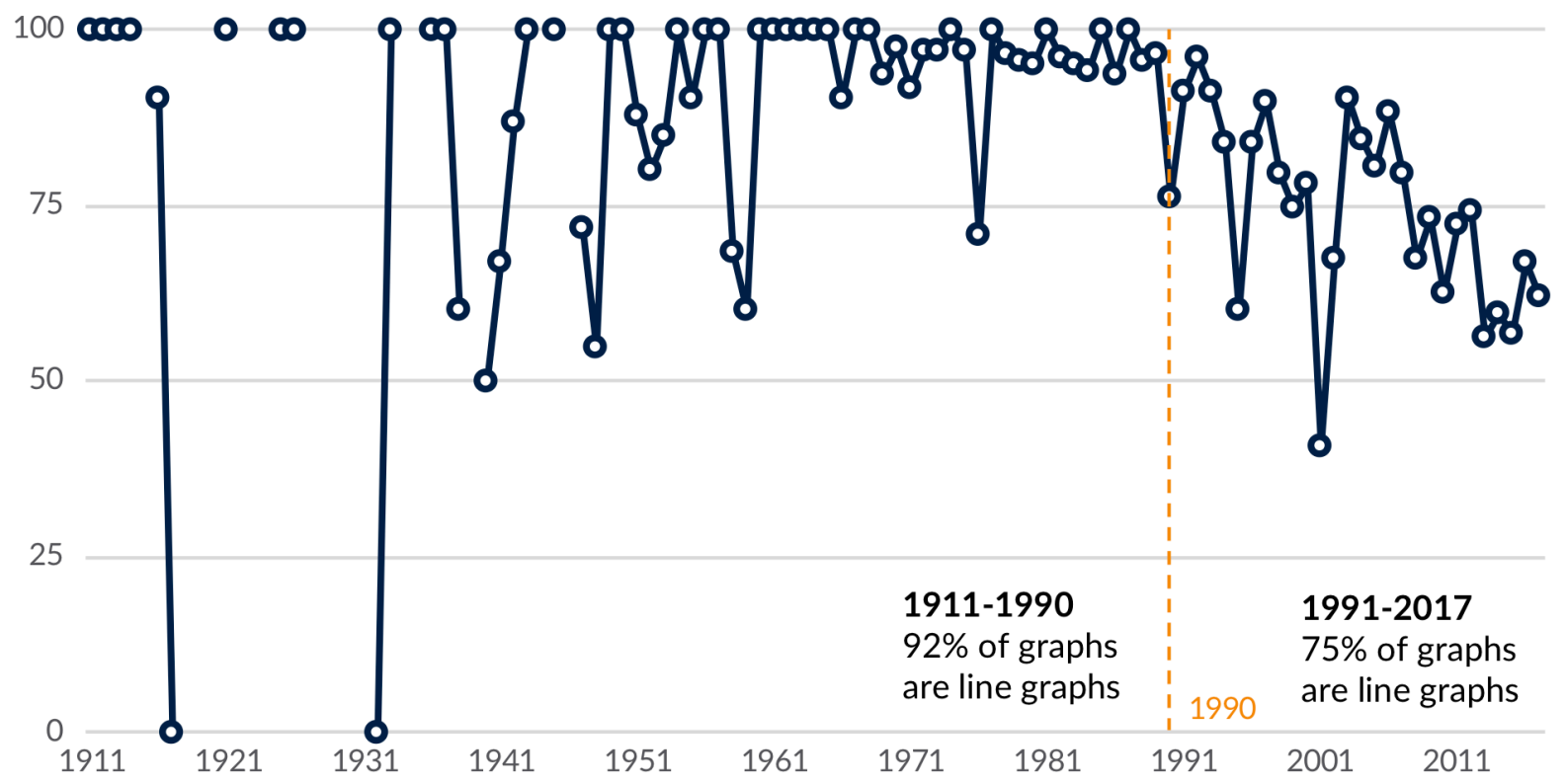

Source: Author's calculations 


\section{Ranking Graph Quality}

Rating a data visualization is inherently subjective. Chart type, colors, line width, font, annotation, and content can all shape a person's view of a visualization and its content (Kong, Liu, and Karahalios, 2018). Furthermore, because any individual Turker may not be familiar with economic data or diagram types (e.g., supply-and-demand), some graphs may be intuitively preferred over others. Because it may also be the case that Turkers are younger on average, there may be some preference towards graphs that appear to be made in modern software tools such as Stata, R, or Microsoft Excel.

Overall, ratings follow a U-shaped pattern, declining between 1911 and around 1960, and then increasing through the end of the period (see Figure 8). There are a few aberrations from this overall pattern, with a sharp drop in 2001-2004 before increasing over the past decade or so. Certain issues in the 1930s had the highest ratings (4.3 in 1933 and 4.2 in 1936) while the fourth issue (1914) with only one graph had the lowest average rating (2.6), followed by a 3.2 rating in 1971. The pattern does not appear to correlate strongly with changes in common software tools such as Excel, SPSS, Stata, or SAS or with changes in the journal, such as editors, page length, or other journals (see the annotations in Figure 3).

Figure 8 shows the number of ratings in each year at each option ( $1=$ bad, $5=$ great) with the overall height of each segment representing the total number of ratings. In other words, the increase in the orange segment at the top of the graph starting around 2009 is the increase in the total number of ratings equal to five. The black, thicker line represents the average rating in each year (with a second-order polynomial fitted on top). (These percentages are tabulated using the mode of the five answers to each graph. In cases of ties-about $30 \%$ of the sample-the higher mode value was used; using the smaller mode did not substantively change the results.)

Figure 8. Average graph ranks fell to a low in the 1960s and then increased through 2017 (Ranking)

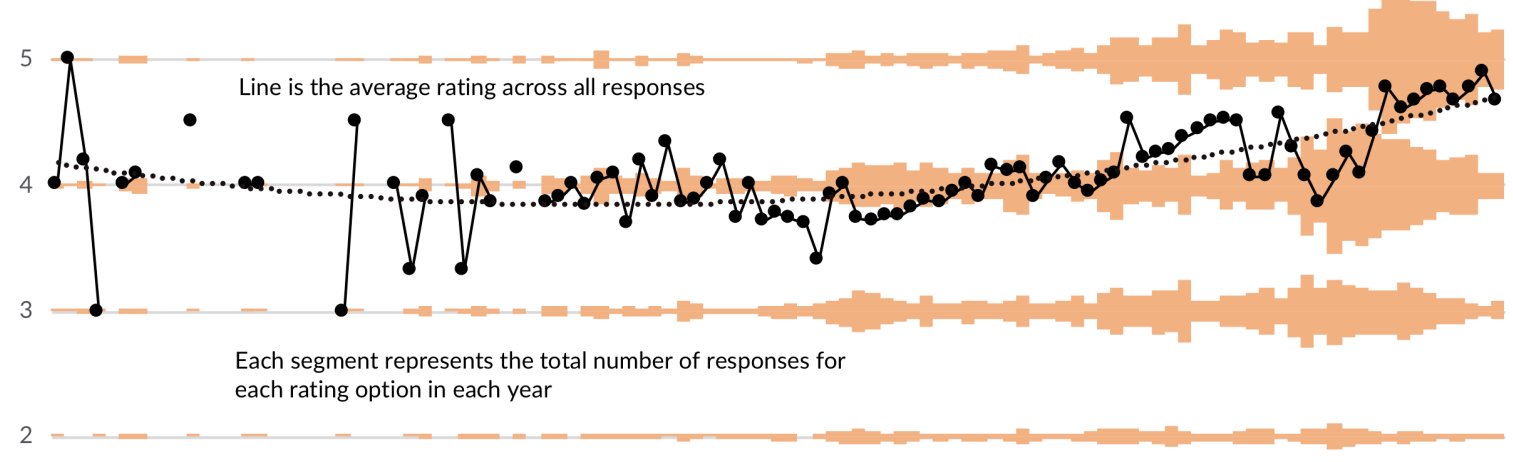

1

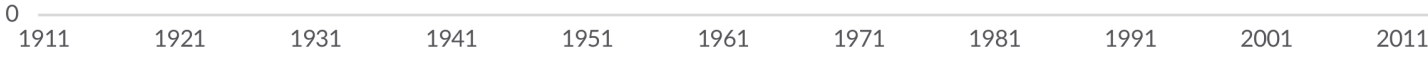

Note: Height of bars represent total number of responses for each rating for all graphs in each year; dots represent average rating in each year. Missing data points reflect no graphs in those years.

Source: Author's calculations. 
The pattern of graph ratings is, however, correlated with categorizations of data-diagram graph types. Over the entire period, the correlation coefficient between the graph quality ratings and the share of graphs classified as made with data is 0.62 . Figure 9 shows this positive correlation with the average rating (calculated across all graphs in each year) on the horizontal axis and the diagram-data graph categorization (also calculated across all graphs in each year) on the vertical axis (the size of the bubbles indicates the number of graphs in each year).

Figure 10. The correlation between ratings and graph type changed around the $1970 \mathrm{~s}$

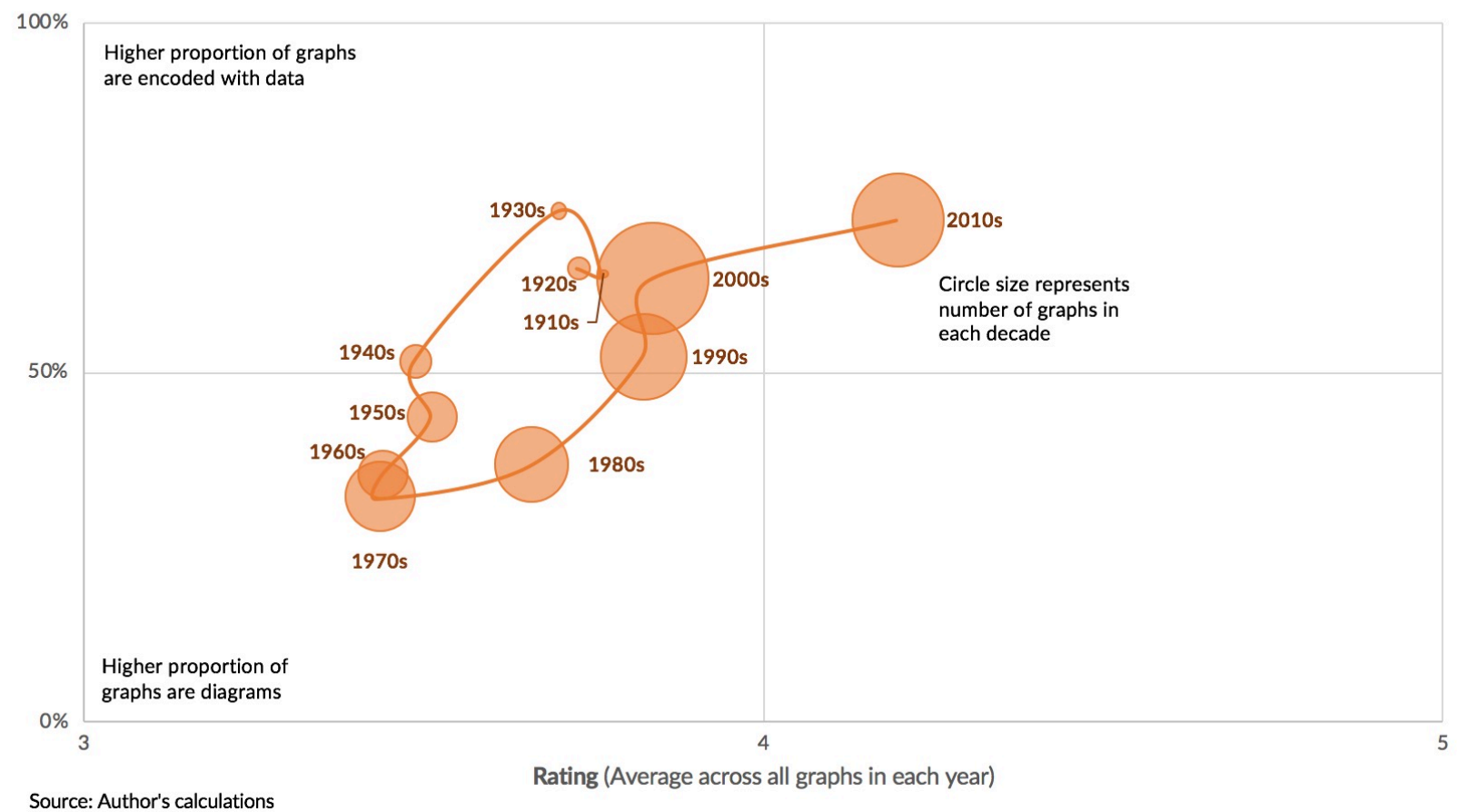

Reflecting these patterns, the relationship between the two variables has changed over time. Figure 10, what is known as a "connected scatterplot", shows the change in the correlations over time (bubbles are sized according to the number of graphs in each decade). The horizontal axis shows the average rating (calculated for each decade) and the vertical axis shows the diagram-data graph type (again calculated by decade). For the $1930 \mathrm{~s}, 1940 \mathrm{~s}, 1950 \mathrm{~s}$, and 1960s decades, average ratings and the probability of being a diagram both decline; between the 1970s and 2010s, both rise.

\section{Conclusion}

This goal of this paper is to neither commend nor critique the quality or type of graphs published in the American Economic Review. Instead, the goal is to try to better understand the types of graphs economists use and the overall quality of those graphs. While there is certainly nothing inherently wrong with line charts, the finding that nearly $80 \%$ of all graphs are line charts begs the question of whether there are more and different graph types economists might use to visually communicate their work. The Ushaped pattern in the type of graph-be it a diagram or encoded with data-may be a useful marker of the development of the economics profession. The U-shaped pattern in 
graph quality could be a true measure of graph quality or may simply be correlated with Turkers' preferences for data-driven graphs or inexperience reading economics graphs.

There are a variety of ways this research might be extended. Graphs could be rated by trained economists, which would help focus the analysis more on the content or graphs could be rated by data visualization experts, which would focus the analysis on the quality of the graphs. Graphs in other journals or even other fields could be explored as well. In any case, this paper is meant to be a potential beginning in exploring the visual history of the field of economics. 


\section{References}

Amazon Mechanical Turk FAQ. https://www.mturk.com/worker/help. Accessed July 2018.

Aumann, Robert J., and Jacques H. Dreze. "Rational Expectations in Games." The American Economic Review 98, no. 1 (2008): 72-86.

http://www.jstor.org/stable/29729964.

Backus, David K., et al. "Dynamics of the Trade Balance and the Terms of Trade: The JCurve?" The American Economic Review, vol. 84, no. 1, 1994, pp. 84-103. JSTOR, JSTOR, www.jstor.org/stable/2117972.

Borkin, M. A., Vo, A. A., Bylinskii, Z., Isola, P., Sunkavalli, S., Oliva, A., \& Pfister, H. (2013). What makes a visualization memorable?. IEEE Transactions on Visualization and Computer Graphics, 19(12), 2306-2315.

Bronfenbrenner, M. (1947). Price Control under Imperfect Competition. The American Economic Review, 37(1), 107-120. Retrieved from http://www.jstor.org/stable/1802861

Card, David and Stefano DellaVigna. 2013. "Nine Facts about Top Journals in Economics," National Bureau of Economic Research Working Paper, No. 18665 (January).

Egan, Mark, Ali Hortaçsu, and Gregor Matvos. 2017. "Deposit Competition and Financial Fragility: Evidence from the US Banking Sector." American Economic Review, 107 (1): 169-216.

Harrison, L., Yang, F., Franconeri, S., \& Chang, R. (2014). Ranking visualizations of correlation using weber's law. IEEE transactions on visualization and computer graphics, 20(12), 1943-1952.

Heckman, J., \& Payner, B. (1989). Determining the Impact of Federal Antidiscrimination Policy on the Economic Status of Blacks: A Study of South Carolina. The American Economic Review, 79(1), 138-177. Retrieved from http://www.jstor.org/stable/1804779

Heer, J., \& Bostock, M. (2010, April). Crowdsourcing graphical perception: using mechanical turk to assess visualization design. In Proceedings of the SIGCHI conference on human factors in computing systems (pp. 203-212). ACM.

Ipeirotis, P. G. (2010). Demographics of mechanical turk.

Kaufman, G. (1969). More On an Empirical Definition of Money. The American Economic Review, 59(1), 78-87. Retrieved from http://www.jstor.org/stable/1811094

Kemmerer, E. (1911). Seasonal Variations in the New York Money Market. The American Economic Review, 1(1), 33-49. Retrieved from http://www.jstor.org/stable/1802906 
López-Córdova, J. Ernesto, and Christopher M. Meissner. "Exchange-Rate Regimes and International Trade: Evidence from the Classical Gold Standard Era." The American Economic Review, vol. 93, no. 1, 2003, pp. 344-353. JSTOR, JSTOR, www.jstor.org/stable/3132179.

Kong, Ha-Kyung, Zhicheng Liu, and Karrie Karahalios. 2018. "Frames and Slants in Titles in Visualizations on Controversial Topics." 2018 CHI Conference.

Kosara, R., \& Ziemkiewicz, C. (2010, April). Do Mechanical Turks dream of square pie charts?. In Proceedings of the 3rd BELIV'10 Workshop: Beyond time and errors: Novel evaluation methods for information visualization (pp. 63-70). ACM.

Medina, J. (2011). Brain rules: 12 principles for surviving and thriving at work, home, and school. ReadHowYouWant.com.

Margo, R. (2011). The Economic History of the "American Economic Review": A Century's Explosion of Economics Research. The American Economic Review, 101(1), 9-35. Retrieved from http://www.jstor.org/stable/41038779

Mason, W., \& Suri, S. (2012). Conducting behavioral research on Amazon's Mechanical Turk. Behavior research methods, 44(1), 1-23.

McGovern, P. D., \& Bushery, J. M. (1999). Data mining the CPS reinterview: Digging into response error. In Federal Committee on Statistical Methodology (Ed.), Federal Committee on Statistical Methodology Research Conference [Proceedings-Monday B sessions] (pp. 7685).

Skau, D., Harrison, L., \& Kosara, R. (2015, June). An evaluation of the impact of visual embellishments in bar charts. In Computer Graphics Forum (Vol. 34, No. 3, pp. 221-230).

Skau, D., \& Kosara, R. (2016, June). Arcs, angles, or areas: individual data encodings in pie and donut charts. In Computer Graphics Forum (Vol. 35, No. 3, pp. 121-130).

Usher, A. (1916). The Influence of Speculative Marketing Upon Prices. The American Economic Review, 6(1), 49-60. Retrieved from http://www.jstor.org/stable/1827811. 


\section{Appendix A. Google Doc for Turkers}

This document contains slightly longer directions to those found in this Amazon Mechanical Turk HIT. There are 7 graphs to categorize and review.

1. Please select whether the graph appears to be made with data or is a diagram or illustration of a theory or concept. For example, this is a conceptual diagram. The author is plotting and labeling the lines, but they don't appear to be directly tied to any data--there are no numbers and no numbers labeling the axes.

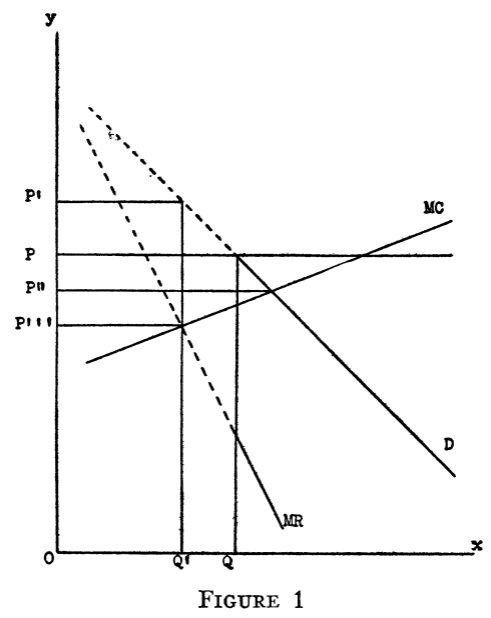

By comparison, this is a standard line chart that is clearly plotting data. There is a legend in the upper-right, years along the $x$-axis, and percentage labels along the y-axis.

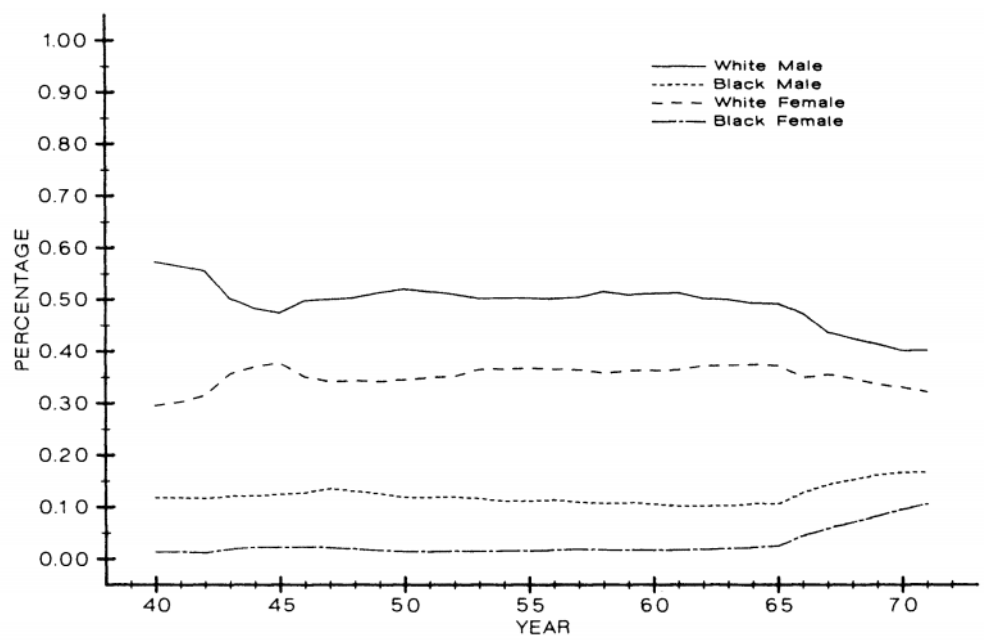

Figure 1. Aggregate Employment Shares in South Carolina Manufacturing 
2. Select the type of graph you see. If the option is not available, please type it in the box. Here are some examples.

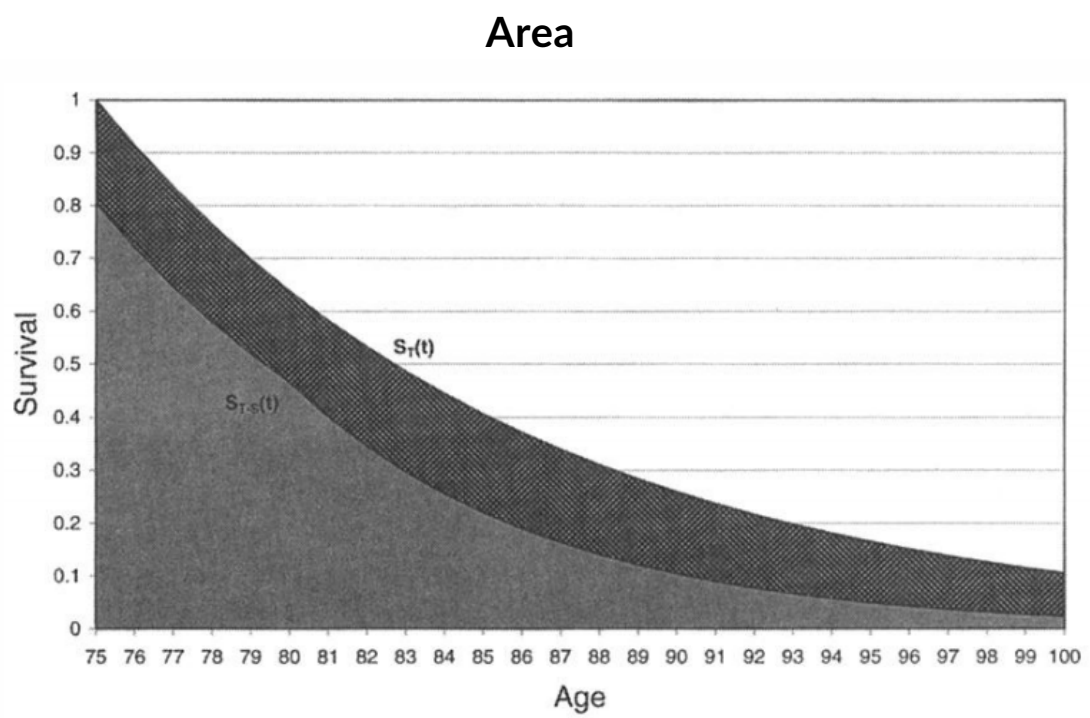

Figure 2. Overall and Healthy Lifetime SuRvival Functions

Bar/Column

CHART III

\section{FREQUENCY OF PRICE CHANGES - $1840-1847$}

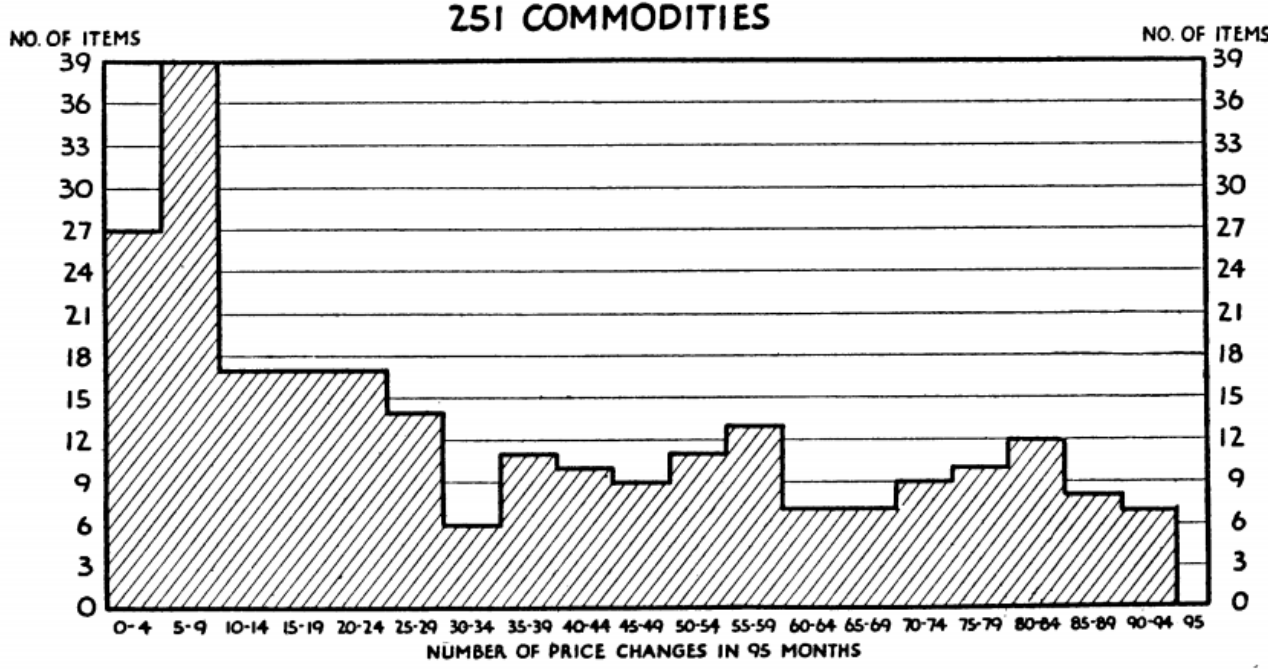

Histogram 


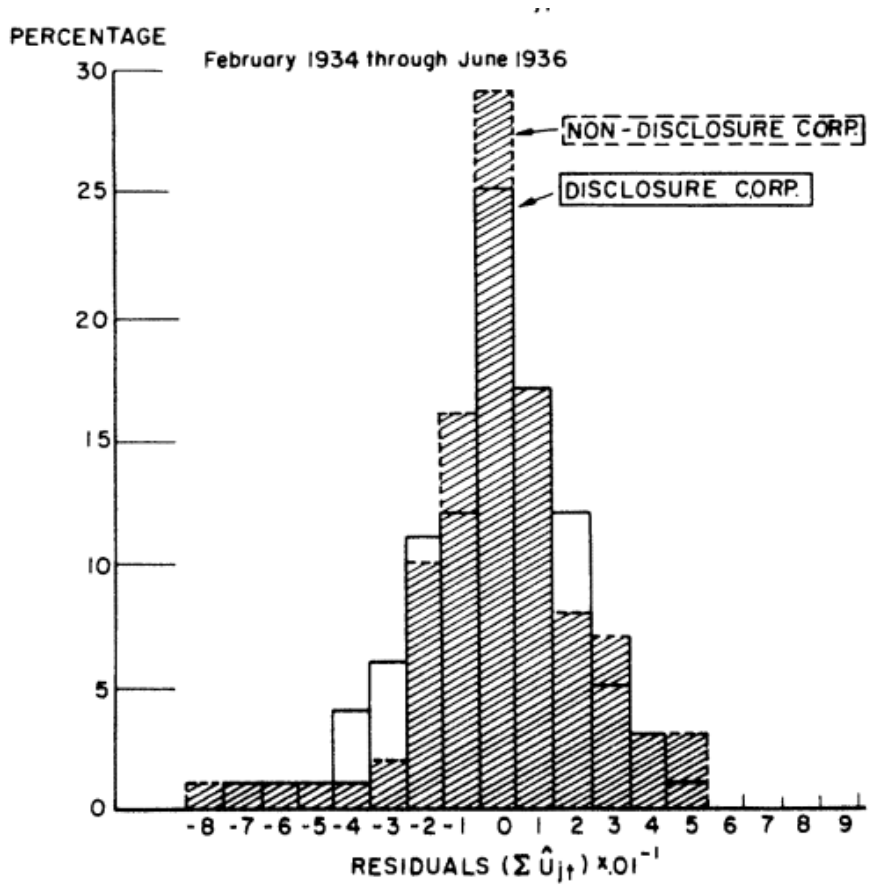

Figure 3. Histograms of CUMUlative Residuals DISCLOSURE AND NONDISCLOSURE CORPORATIONS

\section{Line}

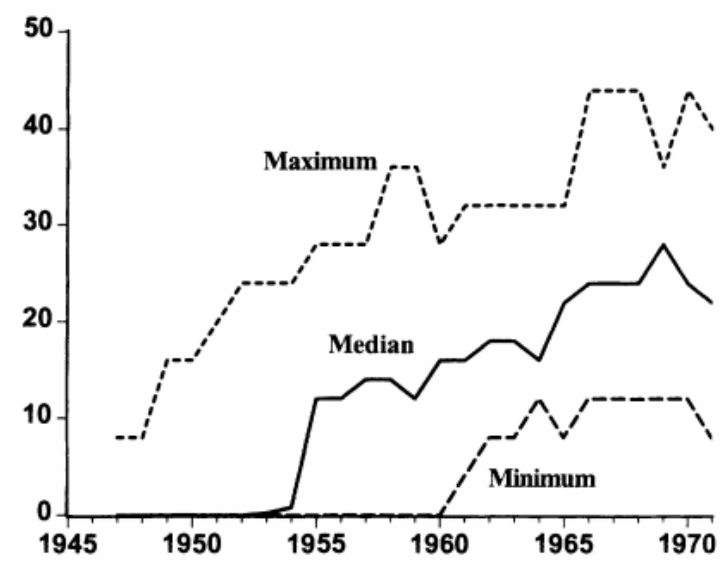

Figure 1. Percentage of Black Players on MLB TEAMS, 1947-1971

Note: Left-hand side is in percentages.

\section{Map}




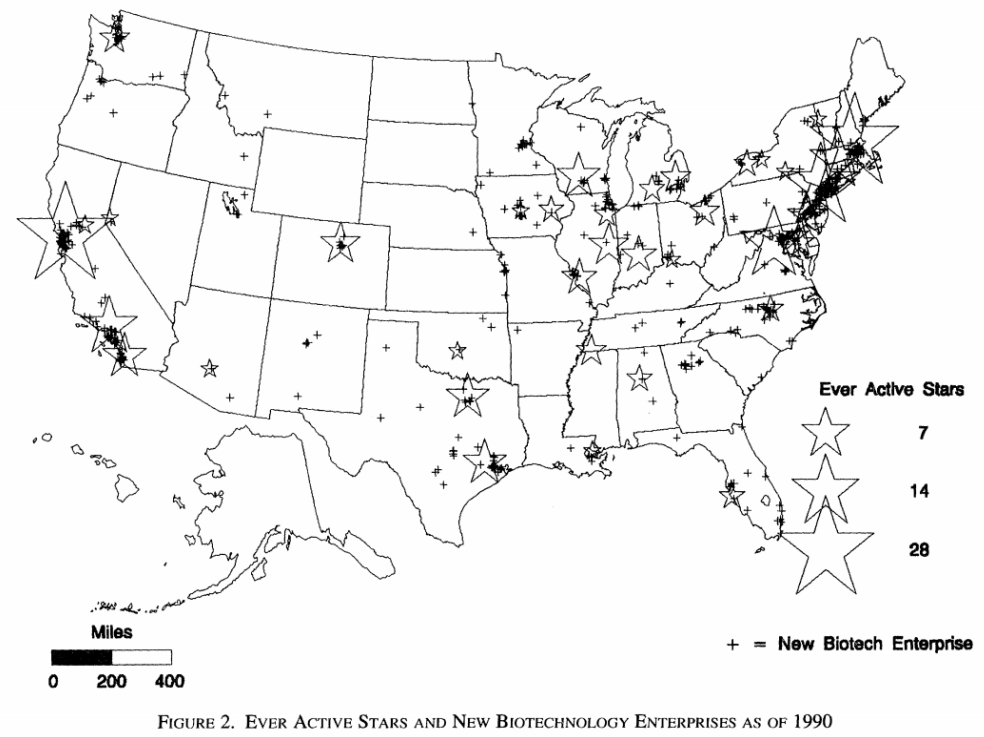

Pie

Chart 1

The Distribution of Income Paid Out to

U.S. Families and Single Persons, 1935-36

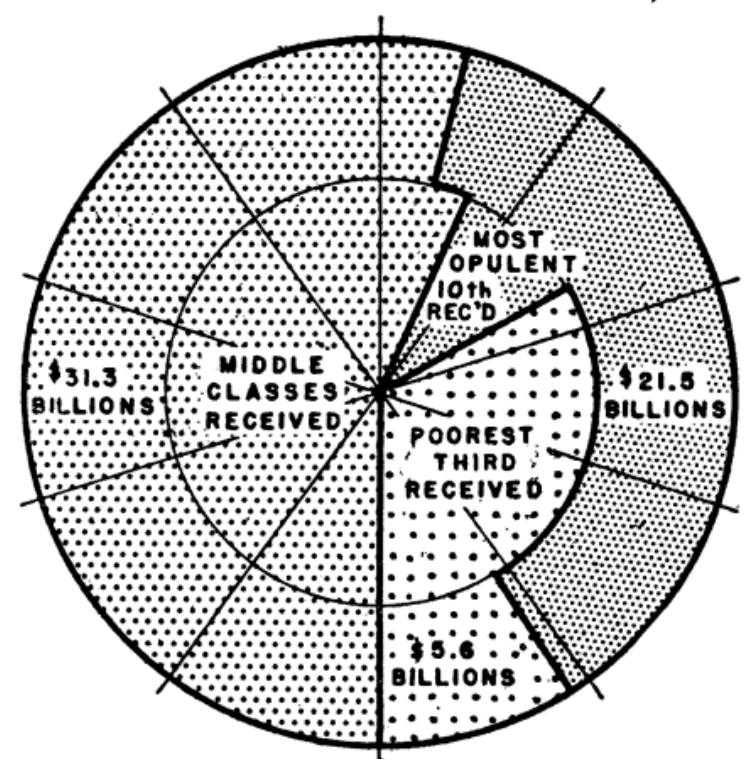

Scatterplot 


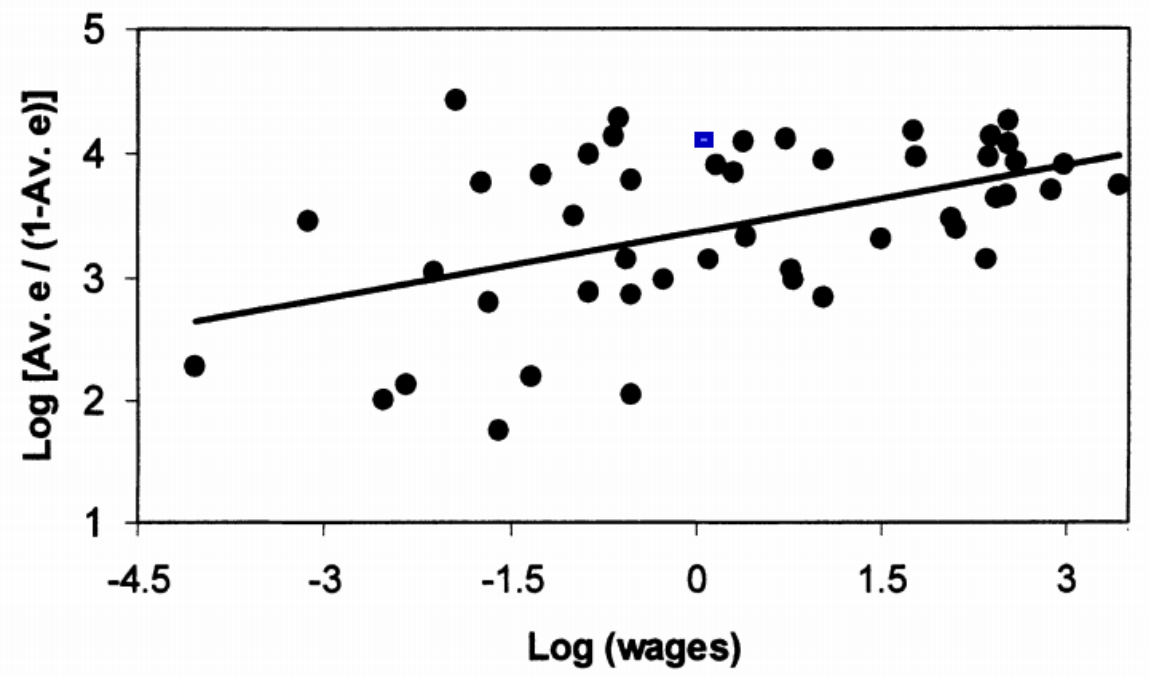

Figure 6. Average Success Rates and Wages (1997)

Table

TABLE 2.-Net charge against fine merino wool produced in the eastern states

\begin{tabular}{|c|c|c|c|c|}
\hline \multicolumn{2}{|c|}{ Pounds of wool } & \multicolumn{2}{|c|}{ Receipts } & \multirow{2}{*}{$\begin{array}{l}\text { A veruge net } \\
\text { charge } \\
\text { against wool } \\
\text { per pound }\end{array}$} \\
\hline Number & $\begin{array}{l}\text { Percentage } \\
\text { of totul }\end{array}$ & $\begin{array}{l}\text { Percentrge } \\
\text { from wool }\end{array}$ & $\begin{array}{c}\text { Percentage from } \\
\text { other sources }\end{array}$ & \\
\hline 37,934 & 6 & 78 & 22 & $\$ 0.42$ \\
\hline 57,083 & 10 & 77 & 23 & .32 \\
\hline 90,886 & 15 & 71 & 29 & .27 \\
\hline 129,169 & 22 & 71 & 29 & .22 \\
\hline 248,519 & 42 & 57 & 43 & .12 \\
\hline 29,588 & 5 & 38 & 62 & .06 \\
\hline 592,979 & 100 & 64 & 36 & .19 \\
\hline
\end{tabular}

\section{Other (Timeline)}

\begin{tabular}{lccc}
0 & 1 & 1.5 & 2 \\
\hline $\begin{array}{l}A \text { and } B \text { choose } \\
o \in\{A, B\}\end{array}$ & $A$ invests $i$ & $\begin{array}{l}\theta \text { is realized and may } \\
\text { be learned by } A\end{array}$ & bargaining
\end{tabular}

Figure 1. The Sequence of Events 

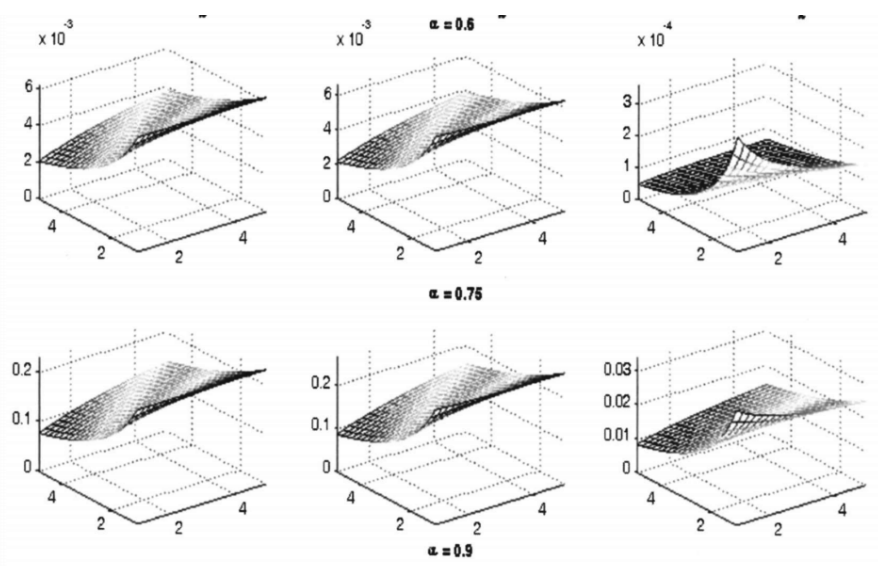

A. First-best vs. optimal policy

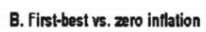

C. Optimal policy vs. zero inflation

Figure 5. Welfare Costs and the Degree of Nominal Price Rigidity

Other (Venn Diagram)

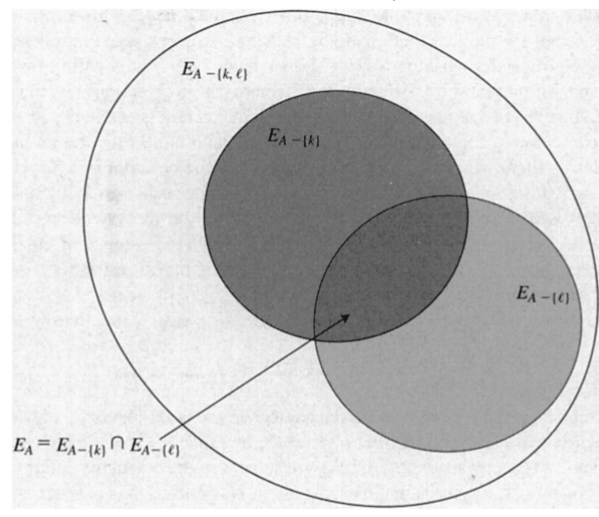

FIGURE 3

Note: Each set $E_{B}$ represents the region of realizations of perturbations making alternative $j$ the utility-maximizing choice Note: Each set $E_{B}$ represents the region of realizations of perturbations making alternative $j$ the utility-maximizing choice
when $B$ is the choice set, so that $p_{j}(B)=\operatorname{Pr}\left(E_{B}\right)$. Both $E_{A-\{k\}} \subset E_{A-\mid k, \ell)}$ and $E_{A-\{\ell\}} \subset E_{A-\{k, \ell)}$ must hold; $K_{j,\{k, \ell)}$ gives the when $B$ is the choice set, so that
probability of the unshaded area.

3. Please rate the graph ( $1=$ bad, $5=$ great) based on your ability to review and understand the graph. This is inherently a subjective question, so make your best judgment based on your perception of the visual. 